\title{
IMPACT OF HORMONAL REPLACEMENT THERAPY ON THE TONGUE MUCOSA OF OVARIECTOMIZED ALBINO RATS RECEIVING TRIPTORELIN
}

\author{
Sally H Abo Baker*
}

\begin{abstract}
Introduction: Menopause is defined as the cessation of menstruation, which is usually common in life's fifth decade in most women. The post-menopausal women usually complain of multifarious oral manifestation that develop overtime. Impact of hormonal replacement therapy not only alleviate the side effects but also enhance the oral wellbeing. However, this needs further research to be more justifiable.
\end{abstract}

Aim of study: 1) to investigate degenerative changes in the tongue epithelium of ovariectomized albino rats and 2) to study the effects of hormonal replacement therapy in attenuation of epithelial cell degeneration.

Materials \& methods: Thirty adult albino female rats were divided into three equal groups: Group I: Control group, Group II: Rats were injected for 75 days with daily dose of $160 \mu \mathrm{g}$ of triptorelin intraperitoneally, Group III: Rats were injected for 75 days with daily dose of $160 \mu \mathrm{g}$ of triptorelin intraperitoneally followed by hormonal replacement therapy of estrogen for 14 days. By the end of the experimental periods all animals were sacrificed and the tongue of all rats were dissected and processed for light and immunohistochemical examinations.

Results: Examination of dorsal surface of rat's tongues in control group revealed normal epithelium with normal taste buds \& connective tissue but the epithelium, taste buds cells and connective tissue in-group II were found to be destructed, group III revealed regeneration of focal areas of destruction that was seen in-group II. Immunohistochemical examination of PCNA expression of control group showed moderate PCNA expression, while group II showed weak PCNA expression, group III showed high PCNA expression.

Conclusion: Hormonal replacement therapy can relieve the oral signs and symptoms and improve the oral well-being in menopausal women.

KEY WORDS: Menopause, Triptorelin, PCNA, Estrogen

* Lecturer of Oral Biology Department, Faculty of Dentistry, Mansoura University, Egypt 


\section{INTRODUCTION}

Menopause is a physiological process of cessation of menstruation permanently for women in their life's fifth decade. ${ }^{(1)}$ It is due to irreversible modifications in female hormonal and reproductive system. Women experience various endocrine changes throughout the menopausal period, especially in the generation of sex steroid hormones that affect their normal well - being. ${ }^{(2)}$

Hormone have a powerful role impact on the development and improvement of the skeletal tissue as well as oral structures. Menopause affects the oral tissues just as it disrupts the body's other systems. Aging as well as hypoestrogenism in menstruation causes alterations in the oral cavity. ${ }^{(3)}$ There is a similarity between the oral mucosa and vaginal mucosa in their histology and response to hormonal therapy in the same manner. Receptors for sex hormone have been identified in the oral mucosa as well as in the salivary organs. ${ }^{(4)}$

Women in menopausal stage often complain of oral discomfort as well as other health problems. The most common complaint found in menopausal and post-menopausal women is the burning mouth syndrome (BMS). It is a chronic condition, in which the patient suffer from burning sensation of the oral mucosa ranging from moderate to severe bilateral with or without the distortion of taste and xerostomia $^{(5)}$.

Triptorelin is a manufactured analog of gonadotropin-releasing hormone $(\mathrm{GnRH})$, which is more intense than the original hormone and relatively safe with proteolysis. It binds strongly on anterior pituitary cells to the GnRH receptor, where it acts like an agonist. It helps in the induction of LH and FSH secretion from the anterior pituitary, but with continuous long-term exposure, secretion can be suppressed by desensitizing the pituitary gonadotropes. It is used in the treatment of malignant neoplasms, central precocious puberty, uterine leiomyoma, endometriosis, advanced prostatic carcinoma, male hypersexuality, and helps in reproductive protocols ${ }^{(6)}$.

However further research need to be carried out to better understand the critical effect of hormonal replacement therapy (HRT) in women during menopause to relieve oral symptoms. Definite guidelines should be available for women during menopause to maintain a great oral well-being and healthy living ${ }^{(2)}$.

Detection of proliferation of cells in tissue section can be observed by many methods. Assessing cell proliferation by immunohistological methods have many advantages over other techniques in that the method is simple with rapid results as well as it maintains the cellular and tissue architecture. ${ }^{(7)}$ PCNA is a $36-\mathrm{KDa}$ protein known as cyclin. It is a special marker for cellular proliferation and found in most cell phases during proliferation ${ }^{(8)}$.

\section{MATERIALS AND METHODS}

Animals: 30 adult albino female rats, with average weight of $200-250 \mathrm{gm}$ used in this study. All experimental methods performed beneath affirmed convention of ethical committee, Faculty of dentistry, University of Mansoura, Egypt. The animals have been housed in individual cage and had received a standard diet for rodents and tap water. The animals were kept in suitable condition like temperature, humidity and life cycle.

Experimental design: the animals were divide equally into three groups:

Group I: rats injected with saline solution intraperitoneally

Group II: rats injected intraperitoneally with daily dose of $160 \mu \mathrm{g}$ of triptorelin for 75 days ${ }^{(9)}$.

Group III: rats injected intraperitoneally with daily dose of $160 \mu \mathrm{g}$ of triptorelin for 75 days, then take hormonal replacement therapy of estrogen (25 $\mu \mathrm{g} / \mathrm{kg} / \mathrm{day}$; sc) for 14 days ${ }^{(10)}$. 
Estrogen (FOLONE ampoules) purchased from Misr Co., for Pharm. ind. S.A.E. (Cairo, Egypt); every $1 \mathrm{ml}$ ampoule contains $5 \mathrm{mg}$ of estradiol benzoate in an oily solution.

Triptorelin is present in the form of triptorelin acetate as an active ingredient under the name of Decapeptyl, which present in the form of one disposable syringe with $1 \mathrm{ml}$ injectable solution; it was purchased from Multi Pharma (Cairo, Egypt)

Serum gonadotropin (oestrogen) was measured at 4 times point during treatment. Blood samples were obtained by cannulation of albino rat's tail artery.

By the end of experimental periods, all animals were sacrificed by exposure to overdose anesthesia. Tongue from each animal was carefully dissected and immediately fixed with $4 \%$ formalin solution and become ready for histological and immunohistochemical study.

\section{RESULTS}

Gross observations: the body weight of the study group animals were increased in relation to the control animals ( table 1), from the data recorded the mean value of the body weight in control group was $201 \mathrm{gm}$ as compared with the mean value of the study group (group II) which was $260 \mathrm{gm}$, the difference between the two values were statistically significant at the level of 5\% ( $\mathrm{T}=4.3)$.

TABLE (1) showing mean value $(\mathrm{x})$ and standard deviation (S.D) of the weight of the study group animals.

\begin{tabular}{|l|l|l|}
\hline & X & S.D \pm \\
\hline Control group & 201 & 17.8 \\
\hline Group II( after 30 days) & 225 & 11.2 \\
\hline Group II( after 60 days) & 240 & 7.9 \\
\hline Group II (after 75 days) & 225 & 11.2 \\
\hline
\end{tabular}

\section{Haematoxylin \& Eosin stain results:}

The histological examination revealed the following:

Group I: The dorsal surface of the tongue had no remarkable changes with normal epithelial cells in the basal and para basal layers with normal thickness of keratin layer. The taste buds had normal histological structure with normal connective tissue papillae.

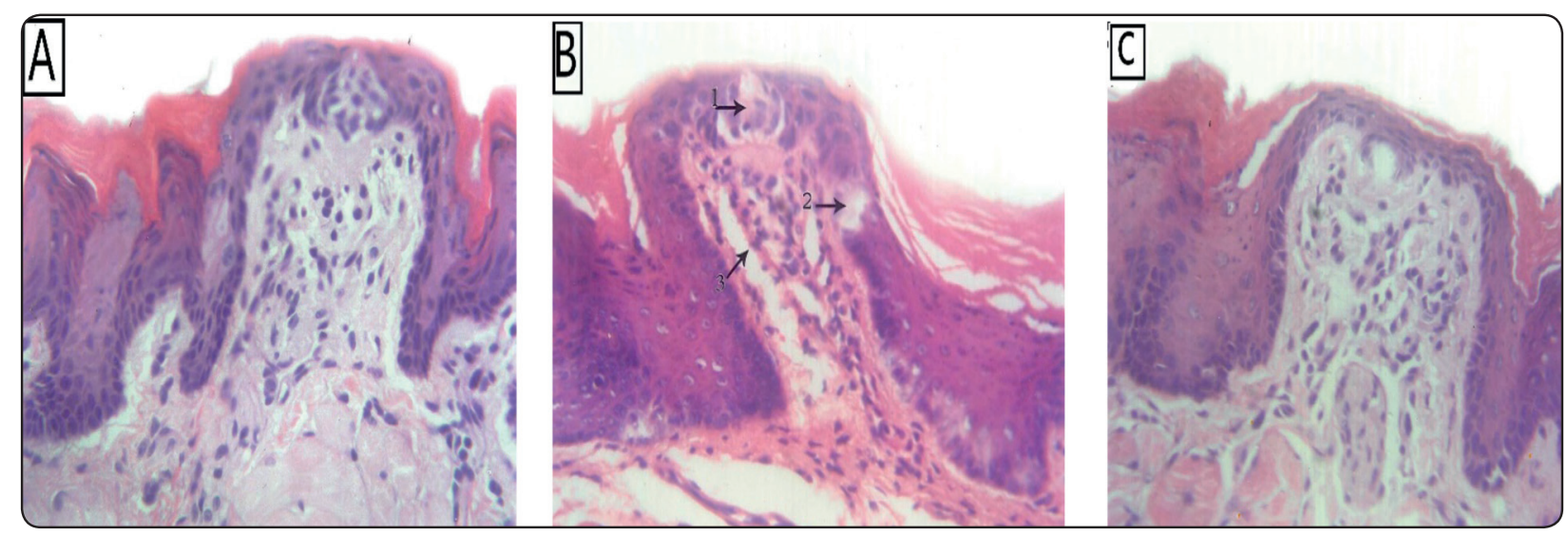

Fig. (1) (A) group I showed the dorsal surface of the tongue had no remarkable changes with normal epithelial cells, normal taste buds and normal connective tissue. (B) Group II showed destruction of taste buds (1), basal cells (2) and connective tissue (3). (C) Group III showed regeneration of focal areas of destruction that encountered in-group II (H\&E x 400) 
Group II: The thickness of the mucosa was apparently thinner in this group than that of control one with irregular and thin keratinized surface. There is focal areas of destruction of taste bud cells, some epithelial cells and connective tissue cells

Group III: The sections showed regeneration of focal areas of destruction that encountered in-group II. The keratin layer increased in thickness with normal architecture of the connective tissue.

\section{Immunohistochemical results:}

Group I: this group show moderate PCNA expression affecting mainly the basal cell layer with mild immunoreactivity of the suprabasal cell layer.

Group II: Negative cells are the predominant in this group. There is weak PCNA expression in the basal cell layer.

Group III: Positive cells are the predominant in this group. This group showed high immunoreactivity of PCNA antibodies.

\section{Statistical results:}

\section{For PCNA labeling index:}

The labeling index for PCNA has been estimated (the number of PCNA positive cells in the basal layer divided by the total number of cell).
TABLE (2) Showing mean value X\& T of all groups.

\begin{tabular}{|c|c|c|}
\hline & $\mathrm{X}$ & $\mathrm{T}$ \\
\hline Group I & 0.51 & \\
\hline Group II & 0.13 & 6.3 \\
\hline Group III & 0.79 & 4.8 \\
\hline
\end{tabular}

By substitution in equation of $\mathrm{T}$ test for all groups under the degree of freedom 8 and at 5\% level of significance where $\mathrm{T}=1.86$

\section{In Group II: $T=6.3$}

There is a significant difference, since 6.3(calculated $\mathrm{T}$ ) is more than $1.86($ tabulated $\mathrm{T})$ we can conclude that at level of significance $5 \%$, group II differs from group I in the average PCNA labeling index.

\section{In Group III: $T=4.8$}

There is a significant difference, since 4.8 (calculated $\mathrm{T}$ ) is more than 1.86 (tabulated $\mathrm{T}$ ) we can conclude that at level of significance $5 \%$, group III differs from group I in the average PCNA labeling index.

\section{Hormonal assay results:}

Rat' blood samples were taken four times for estrogen hormone analysis; the data recorded

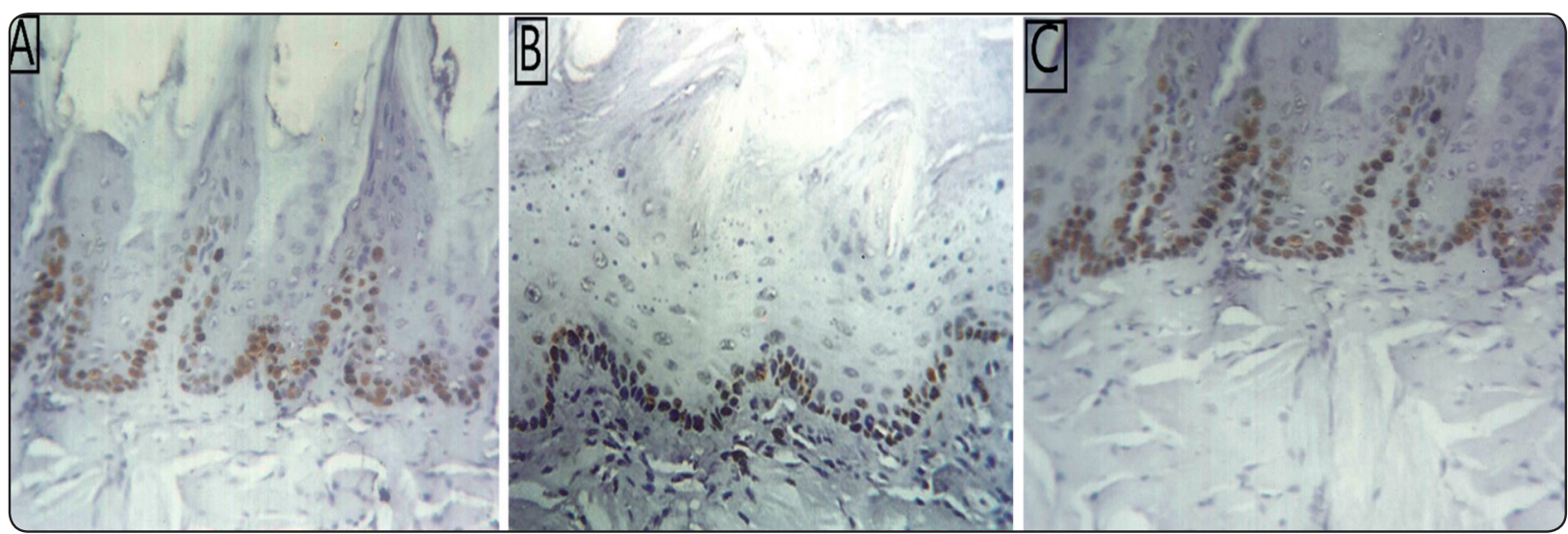

Fig (2) (A) group I showed moderate PCNA expression affecting mainly the basal cell layer with mild immunoreactivity of the suprabasal cell layer, (B) group II showed weak PCNA expression in the basal cell layer, (C) group III showed high positive PCNA reaction (IHC x 400) 
showed gradual decrease of estrogen level as compared with group I (table 3).

TABLE (3) Showing the effect of triptorelin as an ovarian inhibitor on estrogen hormone level in albino rats.

\begin{tabular}{|l|c|c|}
\hline Groups & $\begin{array}{l}\text { Mean value of serum } \\
\text { estrogen level (pg/ml) }\end{array}$ & $\mathrm{T}$ \\
\hline Group I & $39 \mathrm{pg} / \mathrm{ml}$ & \\
\hline Group II (after 7 days) & $45 \mathrm{pg} / \mathrm{ml}$ & 4.5 \\
\hline Group II (after 30 days) & $28 \mathrm{pg} / \mathrm{ml}$ & 5.1 \\
\hline Group II (after 60 days) & $22.4 \mathrm{pg} / \mathrm{ml}$ & 7.2 \\
\hline Group II (after 75 days) & $21.6 \mathrm{pg} / \mathrm{ml}$ & 8.14 \\
\hline
\end{tabular}

By substitution in equation of $\mathrm{T}$ test for all groups under the degree of freedom 8 and at $5 \%$ level of significance where $\mathrm{T}=1.86$

In group II: the calculated $\mathrm{T}$ was more than the tabulated $\mathrm{T}$ in the four stages of hormonal assay, so we concluded that at level of significance $5 \%$, group II differs from group I in the average estrogen hormone level. There is a significant difference.

\section{DISCUSSION}

In the last three decades, the number of cancer survivors has increased due to highly efficient chemotherapy regimens. However, at least one serious side effect of chemotherapy is experienced by $60-75 \%$ of cancer survivors ${ }^{(11)}$ Women can receive triptorelin for many reasons for example invitro fertization, treatment of uterine tumor and treatment of breast cancer. Women who receiving triptorelin will suffer from postmenopausal symptoms as a result of abrupt decline in estrogen level, these symptoms include cardiovascular problems, urogenital disorders, psychosomatic alteration, osteoporosis, hot flush and burning mouth syndrome. ${ }^{(12)}$

The oral cavity is affected directly by hormone levels variations as the oral mucosa contains receptors of estrogen. ${ }^{(4)}$ Tongue was chosen in the present study because it is the most affected organ in menopause by burning tongue sensation. ${ }^{(13)}$

In the present study, the gross finding revealed marked increase in the body weight of group II, III animals that were injected intraperitoneally by daily dose of $160 \mu \mathrm{g}$ of triptorelin for 75 days, which were statistically significant at level of 5\%( $\mathrm{T}=2.0189)$ and $1 \%(\mathrm{~T}=3.9682)$ respectively. These results are in accordance with P.Babaei et al, 2009; they stated that following ovariectomy, estrogen deficiency result in increasing body weight and visceral fat, showing that this hormone substitution could reduce body weight without affecting visceral fat. ${ }^{(14)}$

Arabi,A et al, 2003 found that studies in humans and animals involve estrogen in obesity development. Menopause women with low concentrations of plasma estradiol have a significantly higher waist to - hip ratio (WHR) than menopause women with replacement of estrogen ${ }^{(15)}$

The histological examination of group I revealed normal thickness of the epithelium of dorsal surface of tongue compared with apparently thinner mucosal thickness in group II, these results coincide with Seko K et al, 2005, who observed that deficiency of estrogen may cause mucosal changes, they found that the ovariectomized animals showed reduced mucosal epithelium thickness with an irregular keratinised surface. ${ }^{(16)}$ Our results were supported by Agha-Hosseini $\mathbf{F}$ et al, 2009 who reported that during menopause, the maturation process of the oral epithelium is affected by the reduction in estrogen levels leading to thin and atrophic epithelium. (17)

Examination of group III revealed that the thickness of the mucosa increased with regeneration of the rete pegs, these results coincide with a clinical study evaluating the effectiveness of HRT in postmenopausal patients who suffer from oral dryness or burning, after receiving HRT for 3 months, two-thirds of the women showed significant improvement in the subjective symptoms and in the oral mucosa clinical appearance. ${ }^{(18)}$ HRT can affect 
the oral mucosa just like the vaginal mucosa, as there is similarity between oral mucosa and vaginal mucosa in many ways. ${ }^{(16)}$

The hematoxyline and eosin results of the present study were supported by PCNA immunohistochemical analysis, which showed significant difference between experimental groups. In the same context, Seko K et al, 2005, found that in the overiectomized rat, especially in the tongue apex, the percentage of PCNA positive cells decreased significantly; this indicated that the turnover periods in this region could be delayed, which may lead to oral mucosa thinning in overiectomized rats. ${ }^{(16)}$

Filippe $\mathrm{S}$ et al, 2002 stated that estrogen improves cell proliferation, differentiation and keratinisation of the rat gingival epithelium. ${ }^{(19)}$ It appears that impact of HRT is profoundly individual as some females with symptoms of menopause may benefit from HRT while others do not. ${ }^{20)}$

\section{CONCLUSION}

The current study suggested that HRT might be an effective method for treatment of oral discomfort in postmenopausal women. Therefore, further research is required to assess and verify the impact of HRT on parameters of oral health.

\section{REFERENCES}

1. Roth CL, Neu C, Jarry H and Schoenau E. different effect of agonistic VS. Antagonistic GnRH. Analogues (Triptorelin vs Cetrorelix) on bone modelling and remodeling in peripubertal female rats. Exp clin Endocrinal Diabetes. 2005: 113 (8) 451-6.

2. Vanita Suri, Varun Suri. Monopause and oral health. Journal of Mid Life Health 2014; 5:(3)115-120

3. Lopez BC, Perez MG, Soriano YJ. Dental considerations in pregnancy and menopause. J Clin Exp Dent 2011; 3:135-44.

4. Välimaa H, Savolainen S, Soukka T, Silvoniemi P, Mäkelä $\mathrm{S}$, Kujari H, et al. Estrogen receptor-beta is the predominant estrogen receptor subtype in human oral epithelium andsalivary glands. J Endocrinol 2004; 180:55-62.
5. Nederfors T. Xerostomia and hyposalivation. Adv Dent Res 2000;14:48-56

6. Brian L. Furman Triptorelin xPharm: The Comprehensive Pharmacology Reference, 2007, Pages 1-Reference Module in Biomedical Sciences 2016

7. Levan Muskhelishvili,John R, Latendresse, Ralph L.Kodell \& Eric B Henderson. Evaluation of cell proliferation in rat tissue with Brdu, PCNA, KI-67(MIB-5) Immunohistochemistry and in situ Hybridization for histone mRNA. Journal of histochemistry and cytochemistry,2003:51(12);1681-168

8. Sule bulut, Hilal Uslu, B Handan Ozdemir and Omer Engin Bulut. Analysis of proliferative activity in oral gingival epithelium in immunosuppressive medication induced gingival overgrowth. Head and Face Medicine, 2006 :2-13

9. R. Arriagada, M. G. Le, M. Spielmann, L. Mauriac, J. Bonneterre, M. Namer, T. Delozier, C. Hill1 \& T. Tursz: Randomized trial of adjuvant ovarian suppression in 926 premenopausal patients with early breast cancertreated with adjuvant chemotherapy. Annals of Oncology 2005;16: 389-396.

10. Yu, P. et al.: Attenuation of estradiol on the reduction of striatal dopamine by amphetamine in ovariectomized rats', Journal of cellular biochemistry. Wiley Online Library 2009; 108(6), pp. 1318-1324.

11. Christina AM Mini review. How chemotherapy damages the central nervous system. J Biol 2008; 7:11.

12. C Roth, M Schricker, M Lakomek, A Strege, I Heiden, H Luft, U Munzel, W Wuttke and H Jarry: Autoregulation of gonadotrophin-releasing hormone (GnRH) system during puberty: effect of antagonistic versus agonistic $\mathrm{GnRH}$ in female rat model. Journal of Endocrinology 2001: $169 ; 361-371$

13. Mott AE, Grushka M, Sessle BJ. Diagnosis and management of taste disorders and burning mouth syndrome. Dent Clin North Am. 1993 ;37(1):33-71

14. P. Babaei , A. Damirchi , F. Honarmand, R. Mehdizadeh The Effect of Ovariectomy and Estrogen Replacement on Body Weight and Visceral Adipose Tissue in Rats. 2009, 11(1): 89-95

15. Arabi, A., Garnero, P., Porcher, R., Pelissier, C., Benhamou, C.L., and Roux, C. Changes in body composition during post-menopausal hormone therapy: a 2-year prospective study. Hum Reprod. 2003; 18: 1747-1752 
16. Seko K, Kagami H, Senga K, Ozeki K, Mizutani H, Ueda M. Effects of ovariectomy and estrogen replacement on rat oral mucosa. Maturitas. 2005:10;50(1):44-51

17. Agha-Hosseini F, Mirzaii-Dizgah I, Mansourian A, Khayamzadeh M. Relationship of stimulated saliva 17beta-estradiol and oral dryness feeling in menopause. Maturitas 2009; 62:197-9

18. Volpe A, Lucenti V, Forabosco A, et al. Oral discomfort and hormone replacement therapy in the post-menopause.
Maturitas 1990; 13:1-5.

19. Filippi S, Luconi M, Granchi S, Vignozzi L, Bettuzzi S, Tozzi P, Ledda F, Forti G, Maggi M. Estrogens, but not androgens, regulate expression and functional activity of oxytocin receptor in rabbit epididymis. Endocrinology. 2002;143(11):4271-80

20. Dutt P, Chaudhary SR, Kumar P: Review on Current Knowledge and Associated Dental Management. Annals of Medical and Health Sciences Research 2013;(3):320-323 